EESTI NSV TEADUSTE AKADEEMIA TOIMETISED 1954. III kd., nr. 2 ИЗВЕСТИЯ АКАДЕМИИ НАУК ЭСТОНСКОИ ССР 1954. Том III, 스 2

\title{
ТЕРМОДИНАМИКА ПРОЦЕССОВ ОБРАЗОВАНИЯ И ИЗМЕНЕНИЯ НЕФТЕЙ В ПРИРОДЕ
}

\author{
А. Ф. доБРянскии, \\ член-корреспондент Академин наук Эстонской ССР \\ П. Ф. АНДРЕЕВ, \\ кандидат химических наук
}

Bсе многочисленные варианты гипотезы органического происхождения нефти в качестве исходного нефтематеринского вещества принимают посмертные остатки живых организмов суши и моря. При этом одни исследователи убеждены в том, что нефтематеринское вещество в своей основе имеет циклическую структуру лигнино-гумусового характера. Другие склонны приписывать нефтематеринскому веществу структуру соединений с открытой цепью, имеющей в основе жиры живых существ. Третьи примиряют эти точки зрения, занимая среднюю позицию.

Нет, однако, сомнения в том, что общей тенденцией процессов нефтеобразования является переход от более окисленного органического вещества к менее окисленному. В начале процесса - вещества клетки, с преобладанием в их составе кислородных и азотистых соединений, в конце процесса - нефть, для которой характерна высшая степень восстановленности - углеводороды. Процесс развивается от окисленности органического материала к его восстановленности.

Эта направленность процесса нефтеобразования была известна давно. Количественная, балансовая сторона преобразования исходного органического вещества в нефть также была в свое время предметом исследования одного из нас $\left({ }^{1}\right)$.

Однако энергетическая сторона, термодинамика процесса нефтеобразования и изменения нефтей в природе до последнего времени оставалась в тени, если не считать работ А. В. Фроста и С. Н. Обрядчикова $\left({ }^{9,5}\right)$.

В этих последних работах обсуждается частный вопрос о возможных температурных условиях образования нефти. Термодинамический подход к решению этой, самой по себе сложной задачи позволил авторам дать однозначное решение, ставящее под сомнение многочисленные спекулятивные «теорин» в этой области.

Нет никакого сомнения в том, что термодинамический подход при осмысливании процессов образования и изменений нефти в природе сделает многое ясным и также положит конец пронзвольным толкованиям отдельных стадий этого единого процесса. 
На пути от живой клетки через нефть к метану и графиту и в итоге к углекислоте и воде при выходе на дневную поверхность нам известны начальное и конечное состояние и одно промежуточное - нефть.

Оперируя понятиями энтропии и свободной энергии, термодинамика предсказывает направленность процессов движения вещества и энергии; при этом достаточно знать начальное и конечное состояние, чтобы точно судить о возможности прохождения того или иного процесса в заданных условиях. Термодинамика устанавливает предельные условия для процессов и вовлеченных в них количеств энергин.

Вопрос о соотношении между направленностью и скоростью процесса иногда вызывает путаницу, и здесь уместно, хотя бы в общих чертах, остановиться на этом соотношении. Скорость любого процесса определяется двумя факторами: движущей силой процесса и сопротивлением, внутренним и внешним. Термодинамика может быть применена для определения только движущей силы, но ничего не может сказать о сопротивлении. Следовательно, на основе одной термодинамики нельзя заранее судить о скорости изменения. При химической реакции с помощью термодинамики можно определить максимально возможный выход в данных условиях при неограниченном времени для протекания реакции, но вопрос о действительной скорости, с которой будет происходить реакция для получения этого выхода, термодинамикой не рассматривается. Этот вопрос составляет предмет изучения особой отрасли науки - химической кинетики.

Условия равновесия следует рассматривать как граничные условия систем, в которых одновременно протекают как физические, так и химические изменения. Подобные системы принято называть «действующими» системами, в отличие от систем не действующих, равневесных, в которых не может происходить никаких видимых изменений, если переменные, определяющие состояние системы, не изменяются преднамеренно. Анализируя с точки зрения термодинамики действующие системы, мы получаем результаты значительно более ценные в практическом отношении, чем при рассмотрении идеализированных застывших систем, в которых состав и температура предполагаются повсюду постоянными. Примером действующей системы, которая может быть с успехом исследована с помощью термодинамики, является система из захороненного органического вещества, сопутствующей ему воды и окружающей породы, или также система нефть-вода-порода.

Детальным изучением процессов в живых тканях было установлено, что основные законы неживой породы целиком приложимы и к организмам $\left({ }^{4}\right)$.

Характерной особенностью живой клетки и первым признаком живого вещества является обмен веществ. В результате этого обмена живая растительная клетка, поглощая из неживой природы некоторые простейшие вещества, как, например, углекислоту, воду и другие, строит из них с помощью получаемой извне солнечной энергии сложные соединения своего организма. С точки зрения термодинамики, в результате этого процесса энтропия системы уменьшается, а количество энергии, приходящееся на один атом углерода, увеличивается.

Таким образом, если в неживой природе все процессы стремятся в направлении увеличения энтропии и к снижению запаса энергии в соединении, то в живой клетке наблюдается обратное. Это не значит, конечно, что законы термодинамики не приложимы к живой клетке. Процессы построения в живой клетке сложных соединений с большим запасом энергии и уменьшением энтропии сопровождаются процессами поглощения энергии извне (солнце) или процессами разрушения сложных 
веществ, поступающих также извне в виде пищи и несущих с собой запас энергии высокого потенциала. Последнее имеет место для клеток животного организма, не способного непосредственно усваивать солнечную энергию.

Поступающая извне энергия далеко не полностью переходит во вновь создаваемые вещества живой клетки. Большая часть ее идет на поддержание жизненных процессов или вообще не усваивается организмом. В целом в системе живая клетка-внешний источник энергии энтропия также увеличивается.

Раньше или позже наступает естественная смерть организма. К моменту прекращения жизненных функций в клетке всегда имеется известный запас сложно построенных органических соединений. Посмертные изменения этих соединений, самопроизвольные процессы дальнейшего движения материи совершаются уже по законам неживой природы. Начинается самопроизвольный распад сложных соединений, термодинамически неустойчивых в условиях окружающей среды. Естественно, что конечным результатом этого процесса будут продукты полной минерализации - углекислота, вода, азот и др. соединения, равновесные в условиях поверхности земной коры. Запас энергии при этом уменьшается, энтропия увеличивается. Например, простейшая амино-кислота - глицин (аминоуксусная кислота) имее свободную энергию $\Delta \mathrm{F}_{298}^{\circ}=$ $=-88580$ кал/моль, а получающиеся в результате ее полной минерализации углекислота, вода и азот имеют, соответственно, свободные энергии - 94206 , - 56690 и 0 кал/моль. В итоге окисления и распада глицина потеря свободной энергии составляет 241665 кал/моль. В итоге окисления глюкозы до углекислоты и воды потеря свободной энергии составит 688160 кал/моль.

Процесс приближения к равновесному состоянию в условиях земной коры не всегда идет прямо и до конца. Попадая в особые условия, сложные органические соединения могут остановиться на своем пути к углекислоте и воде. Такой остановке мы и обязаны наличием на земле каустобиолитов.

Выше мы отмечали, что процесс образования нефти (и вообще каустобиолитов) по существу представляет собой процесс восстановления кислородных соединений живых организмов. Одним из непременных условий этого процесса является отсутствие в системе окислительных агентов - в частности кислорода. Это условие, как известно, реализуется при захоронении посмертных остатков живой клетки под толщей минеральных осадков.

Возникает термодинамическая гетерогенная система из трех фаз: органическое вещество-вода-порода. В свою очередь, каждая из этих фаз не представляет собой чего-то единого. Органическое вещество разнородно по составу, вода всегда содержит растворенные соли, порода включает в себя многочисленные минералы. Однако в первом приближении можно ограничиться таким рассмотрением системы, имея в виду наличие поверхностей раздела внутри ее. Последнее является, как известно, определяющим признаком фазы термодинамической системы.

Естественно, что процессы в такой системе могут протекать лишь на поверхностях раздела фаз, и, следовательно, скорости процессов будут определяться в основном скоростями диффузии вещества к поверхности раздела. Заметим, что масса каждой фазы, взятой в отдельности, не влияет на состояние равновесия.

Только что сложившаяся гетерогенная система представляет собой неравновесную систему. В ней тотчас же начинают развиваться процессы, в итоге полной реализации которых система в сложившихся условиях 
может прийти в равновесное состояние. Такого рода системы мы выше назвали действующими системами.

Как известно, состояние равновесия в термодинамических системах характеризуется максимальными значениями энғропии и минимальными значениями термодинамического потенциала или свободной энергии.

Следовательно, и наша система будет самопроизвольно развиваться в направлении увеличения энтропии и снижения термодинамического потенциала или запаса свободной энергии.

C перекрытием осадка новыми порциями материала в нижележащих слоях возникают восстановительные условия. Запасы свободного, раство-

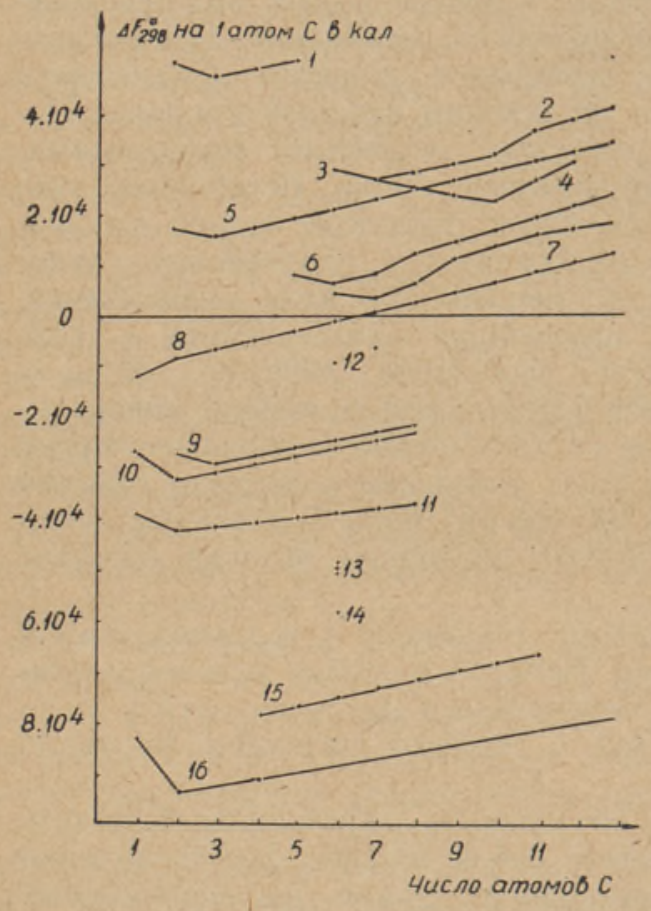

Рис. 1. 1-Ацетиленовые углеводороды, 2-алкилбензолы, 3 - бензол, 4 - полиметилбензол, 5 - олефины, 6 -циклопентановые углеводороды, 7 - циклогексановые углеводороды, 8 - нормальные парафины, 9 - простые эфиры, 10 - альдегиды, 11 - спирты, 12 - фенол и бензиловый спирт, 13 - диоксибензол, 14 - бензоя̆ная кислота, 15 - гложные эфиры, 16 кислоты жирного ряда. ренного в воде и адсорбированного твердыми частицами кислорода быстро исчерпываются.

Во время миграции органическое вещество пребывает в окислительной обстановке. В осадок попадает окисленное вещество, для которого характерно наличие кислотных, фенольных, гидроксильных и других кислородсодержащих групп. С термодинамической точки зрения такие соединения стоят по значениям свободной энергии на уровне значений $\Delta \mathrm{F}_{298}^{\circ}$ от - 110000 до - 70000 кал/моль, т. е. образование их из элементов сопровождалось значительным выделением энергии. В окислительной среде на дневной поверхности такие соединения устойчивы.

Однако, попадая в восстановительную среду, органическое вещество приходит с этой средой в противоречие. Система органическое окисленное вещество-порода-вода становится неравновесной, действующей. В системе возникают прощессы, стремящиеся сгладить эти противоречия, привести систему снова в равновесное состояние.

Общей направленностью этих процессов будет исчезновение групп, характерных для окисленного состояния, и возникновение в структуре сложной молекулы все более и более восстановленных участков. На шкале свободных энергий органических соединений (рис. 1) [рис. 1 составлен на основании литературных данных $(3,6,7)]$ это видно особенно наглядно. Поднимаясь вверх от многоатомных спиртов и кислот, мы будем проходить зону сложных эфиров, ацеталей через зону одноатомных спиртов, кетонов и простых эфиров к углеводородам парафинового ряда. Величина свободной энергии последних близка к ее нулевым значениям.

Описанный нами выше процесс закономерен для органических веществ с цепеобразной структурой углеродного скелета. На своем восстановительном пути эти соединения не могут не пройти стадии углеводородов метанового ряда. А эти последние в восстановительных условиях являют- 
ся вполне устойчивыми, близкими, как мы видели, к нулевым значениям свободной энергии. Перейти нулевые значения свободной энергии в среде с невысоким восстановительным потенциалом к соединениям циклической структуры - метановым углеводородам будет невозможно из-за недостатка свобоодной энергии в системе. Посмотрим на энергетическую сторону этого процесса. При восстановлении пальмитиновой кислоты $\mathrm{C}_{16} \mathrm{H}_{32} \mathrm{O}_{2}$ до углеводорода пентадекана $\mathrm{C}_{15} \mathrm{H}_{32}$ непосредственным отщеплением углекислоты

$$
\mathrm{C}_{15} \mathrm{H}_{31} \mathrm{COOH} \rightarrow \mathrm{C}_{15} \mathrm{H}_{32}+\mathrm{CO}_{2}
$$

изменение свободной энергии составит $\left({ }^{6}\right)$ :

$\Delta F^{\circ}{ }_{298}=\quad \begin{array}{crc}\mathrm{C}_{16} \mathrm{H}_{32} \mathrm{O}_{2} & \mathrm{C}_{15} \mathrm{H}_{32} & \mathrm{CO}_{2} \\ -78560 & -765130 & -94260\end{array}$

Разность первой величины и суммы двух последних - 430 кал, т. е. реакция сопровождается уменьшением свободной энергии на 430 кал/моль. Для этого процесса нужно найти внутри нашей действующей системы источник энергии высокого потенциала, чтобы преодолеть «энергетический барьер» начала реакции. В окружающей среде таких источников нет.

Известно, например, что реакция образования хлористого водорода из элементов

$$
\mathrm{H}_{2}+\mathrm{Cl}_{2} \rightarrow 2 \mathrm{HCl}
$$

сопровождается уменьшением свободной энергии на 22610 кал/моль. Однако эта реакция может начаться лишь при особых условиях, например при освещении или под воздействием катализаторов. В темноте и в отсутствии катализаторов смесь водорода и хлора может сколь угодно долго оставаться без изменения.

Для циклических соединений переход от окисленного к восстановленному состоянию отнятием кислорода сопряжен с затратой энергии. Например, переход от циклогексанола к циклогексану связан с возрастанием свободной энергии на 39010 кал/моль.

Углеводороды с высокими положительными значениями свободной энергии являются неустойчивыми и имеют тенденцию самопроизвольно переходить в соединения с пониженными значениями свободной энергии, в конечном счете - к парафиновым углеводородам. В условиях слабовосстановительной среды эти последние являются наиболее устойчивыми. Так, например, при переходе от циклогексана к гексану свободная энергия уменьшается на 6950 кал/моль, переход от бензола к гексану дает уменышение свободной энергии в 30620 кал/моль и т. д.

Нашу действительную систему не будет неуместным уподобить чувствительным весам. Будучи выведенной из состояния равновесия (с энергетической точки зрения), первая же реакция с выделением энергии в нашей системе повлечет за собой реакцию с поглощением энергии. Система все более будет приходить к состоянию равновесия, все время переходя в целом через нулевые значения свободной энергии и все более уменьшая энергетическую амплитуду колебаний.

Раскрытие цикла освободит известное количество энергии, которая пойдет внутри системы на восстановление еще окисленных соединений. В свою очередь, такими могут оказаться снова циклические соединения и соединения метанового ряда. Первые дадут циклические углеводороды, способные с дециклизацией отдать, в свою очередь, в систему уже несколько уменьшенное количество энергии. Вторые же, с цепеобразным строением, будут своеобразными акцепторами энергии и, перейдя в восстановленное состояние, уже не отдадут энергии в систему. С исчерпанием запасов цепеобразных соединений - акцепторов энергии, эта их последняя роль акцептора переходит к окружающей среде. С обеих сто- 
рон система приходит к положению равновесия - к углеводородам метанового ряда. Баланс по водороду для этих процессов уже описан с исчерпывающей полнотой ( $\left.{ }^{1}\right)$.

Реакцию перехода фенола в бензол можно условно записать как процесс отщепления кислорода. Для фенола известно, что он дает хорошие выходы бензола нагреванием, например с оловом, всего лишь до $100^{\circ}\left({ }^{2}\right)$.

Реакцию образования бензола из фенола можно представить себе также и как процесс диспропорционирования гидроксильных групп, что известно для окси-соединений:

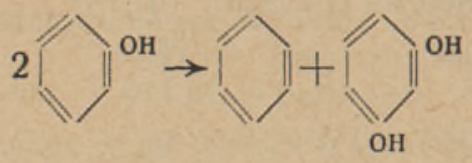

Для этой схемы изменение свободной энергии имеет отрицательное значение. Соответственно:

$$
\begin{aligned}
& 2(-9740) \rightarrow(+29580)+(-50000)= \\
& -19480 \rightarrow-20420=-940 \text { кал/моль. }
\end{aligned}
$$

Интересно и важно иметь в виду, что изменение свободной энергии в результате реакций диспропорционирования водорода по мере укрупнения молекул углеводородов все более стремится к нулю. Так, например, реакция диспропорционирования водорода у простого углеводорода пропена

$$
2 \mathrm{CH}_{3}-\mathrm{CH}=\mathrm{CH}_{2} \rightarrow \mathrm{CH}_{3}-\mathrm{C} \equiv \mathrm{CH}+\mathrm{CH}_{3}-\mathrm{CH}_{2}-\mathrm{CH}_{3}
$$

сопровождается увеличением свободной энергии на 10880 кал/моль. Для реакции

$$
\begin{aligned}
& 2 \mathrm{CH}_{3}-\mathrm{CH}_{2}-\mathrm{CH}_{2}-\mathrm{CH}=\mathrm{CH}_{2} \rightarrow \mathrm{CH}_{3}-\mathrm{CH}_{2}-\mathrm{CH}_{2} \\
& \mathrm{CH}_{2}-\mathrm{C} \equiv \mathrm{CH}+\mathrm{CH}_{3}-\mathrm{CH}_{2}-\mathrm{CH}_{2}-\mathrm{CH}_{2}-\mathrm{CH}_{3}
\end{aligned}
$$

это увеличение составляет уже 10630 кал/моль. К сожалению, для более сложных молекул отсутствуют надежные термодинамические данные и точный расчет пока невозможен. Однако общая тенденция достаточно ясна, особенно если иметь в виду рис. 1.

Еще более наглядно эта тенденция выступает при идущем до конца диспропорционировании водорода, до образования в результате этого графита и метана. Қак известно, для метана $\Delta \mathrm{F}_{298}=-12140$ кал/моль, а для графита $\Delta \mathrm{F}_{298}^{\circ}=0$ кал.

Следовательно, распад всякого углеродистого соединения до графита и метана будет связан с резким уменьшением величины свободной энергин. Следовательно, процессы диспропорционирования водорода в углеводородах с образованием графита и метана являются термодинамически закономерными. Чем сложнее соединение, тем температура начала процессов диспропорционирования водорода для него ниже.

Естественно возникает вопрос, почему же многие соединения, обладающие положительными значениями свободной энергии, являются стабильными в течение известного промежутка времени, как, например, бензол?

Здесь дело касается уже другой стороны вопроса - вопроса о химической стабильности того или иного соединения, что целиком объясняется особенностями строения их молекул. Строго говоря, тот же бензол является термодинамически неустойчивым в обычных условиях. Однако, чтобы началась реакция его самопроизвольного распада на элементы, необходимо подвести какое-то количество энергии, активировать молекулу бензола, вывести ее из инертного состояния. Такой энергией может быть тепловая энергия, энергия фотонов, энергия быстрых частиц и др. Необ- 
ходимо преодолеть некоторый энергетический барьер, перейдя за который молекула уже будет реакционноспособна и начинается ее самопроизвольный распад. Подобные примеры хорошо известны. Нагревание, облучение «жесткими» квантами света, $\alpha$-частицамиं радиоактивного распада приводят к разрушению молекул с образованием элементов.

Ту же роль в известных условиях могут исполнять катализаторы, роль которых, как известно, сводится к ускорению термодинамически возможных реакций.

Из термодинамики известно, что свободная энергия органических соединений зависит как от агрегатного состояния вещества, так и от температуры. Во всех наших вышеприведенных рассуждениях мы оперировали со стандартными значениями величин свободных энергий, т. е. при температуре $+25^{\circ} \mathrm{C}$ и давлении 1 ат. Агрегатное состояние - жидкость. Надо при этом заметить, что зависимость величин свободной энергии от температуры не так уже велика и в диапазоне температур от 0 до $100^{\circ} \mathrm{C}$ значительных изменений свободная энергия не испытывает. Поэтому все наши выводы справедливы для той области температур, в которой происходят процессы образования и изменения нефти в природе. Что же касается зависимости величины свободной энергии от давления, то последняя главным образом сказывается на веществе в газообразном состоянии. Для жидкого состояния вещества эта зависимость практически не заметна, особенно в интервале 1 - 200 ат. Процессы же образования и превращения нефти в природе проходят именно в этом интервале давлений.

Рассмотрим термодинамически возможные направления реакций при определенных нами выше температурах и давлениях. Это особенно важно еще и потому, что, как известно, существуют две диаметрально противоположные точки зрения в этом вопросе. Первая точка зрения состоит в том, что исходный органический материал для нефтеобразования имел сложное циклическое строение из конденсированных ядер. Промежуточные продукты на пути от этого материала к собственно нефти имели также циклическое строение.

Процесс изменения нефти в природе и состоит по этой теории, между прочим, в том, что с геохимическим возрастом нефти происходят все более далеко идущие процессы дециклизации, приводящие к накоплению в нефти углеводородов метанового ряда. Процессы дециклизации связаны с параллельно идущими при этом процессами восстановления, точнее потерями кислорода, а также распадами длинных цепей на более короткие.

Итогом естественного метаморфизма нефтей является метан и графит.

Другая точка зрения исходит из прямо противоположных предположений. Основой ее является возрождение известной гипотезы Энглера о происхождении нефти из жиров растительных и животных организмов. Если опустить всем известные детали этой,гипотезы, то с химической стороны она выглядит так: гидролиз жиров дает в итоге кислоты жирного ряда. Последние, декарбоксилируясь, дают углеводороды метанового ряда. Полупродукт между исходным органическим веществом и нефтью имеет в своей основе строение метановых углеводородов. В дальнейшем происходит циклизация метановых углеводородов с образованием циклопарафиновых и ароматических углеводородов. Итогом естественного метаморфизма нефтей является асфальт и подобные ему минералы циклического строения.

Выше мы убедились, что в условиях невысоких температур и давлений возможны, с термодинамической точки зрения, только лишь реакции дециклизации. Обратные реакции, связанные с возникновением циклов, термодинамически незакономерны. 
C повышением температуры свободные энергии органических соединений стремятся к нулевым значениям. Так, например, для метана зависимость свободной энергии от температуры выражается уравнением

$$
\Delta \mathrm{F}^{\circ}=-19450+23,0 \mathrm{~T} \text {. }
$$

При температуре $845^{\circ} \mathrm{K}$ (или $572^{\circ} \mathrm{C}$ )

$$
\Delta \mathrm{F}^{\circ}=0 \text {, }
$$

т. е. метан диссоциирует на элементы. Прямой опыт подтверждает это.

Вообще для парафинов эта зависимость имеет следующий вид:

$$
\Delta \mathrm{F}^{\circ}=-(14700-6000) \mathrm{n}+1,0 \mathrm{~T}+25,0 \mathrm{nT},
$$

где $\mathrm{n}$ - число атомов углерода в молекуле, T - абсолютная температура.

Для циклогексана

Для бензола

$$
4 \mathrm{~F}^{\circ}=+33600+136,4 \mathrm{~T}
$$

$$
\Delta \mathrm{F}^{\circ}=+17900 \div 41,7 \mathrm{~T} \text {. }
$$

Будучи представлены графическим путем (рис. 2), эти зависимости позволяют сделать несколько полезных заключений.

Метан является наиболее устойчивым углеводородом. Относительная

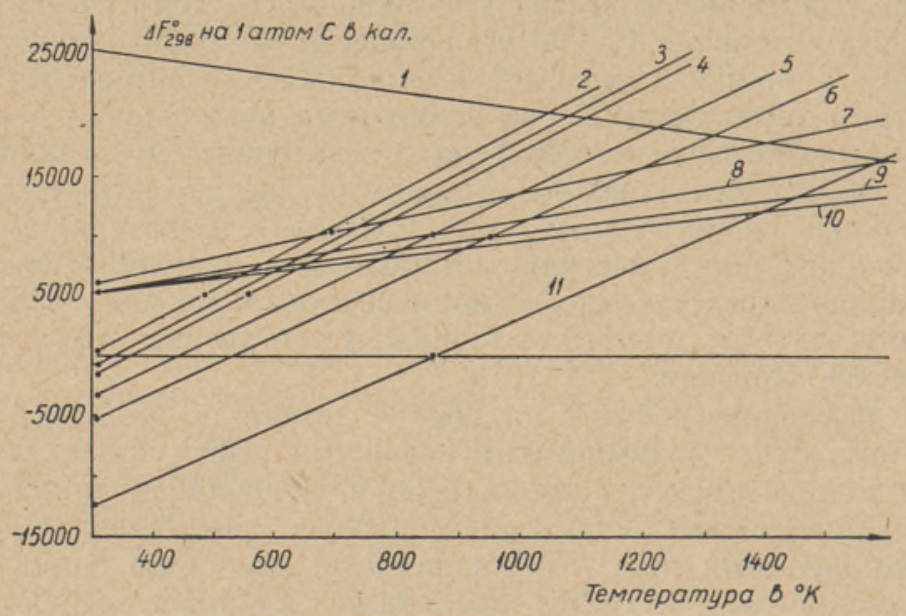

Рис, 2. I- Ацетилен, 2 - тетрадекан, 3 - октан, 4 - гексан, 5 - пропан,

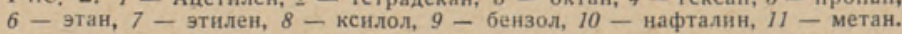

устойчивость уменьшается в гомологическом ряду при переходе к высшим членам ряда. Кривая циклогексана не отличается значительно от кривой $\boldsymbol{w}$-гексана, следовательно, по термодинамической устойчивости эти ряды углеводородов более близки друг к другу, чем к ароматическим соединениям (рис. 2).

И, наконец, в качестве основного вывода легко видеть, что парафиновые и полиметиленовые углеводороды сравнительно более устойчивы при низких температурах (ниже $500^{\circ} \mathrm{K}$ ), в то время как ароматические и олефиновые более устойчивы при высоких температурах. Для углеводородов всех рядов (за исключением ацетилена) стабильность с увеличением температуры падает, и при температуре выше $850^{\circ} \mathrm{K}$ ни один углеводород не является термодинамически устойчивым по сравнению с элементами.

Несложные расчеты показывают, что для реакции гидрирования с разрывом гексаметиленового цикла 


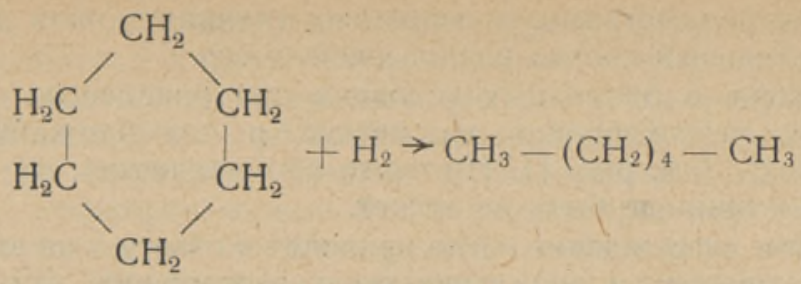

$$
\Delta \mathrm{F}^{\circ}=-17100+14,6 \mathrm{~T}
$$

и, следовательно, при любой температуре ниже $1070^{\circ} \mathrm{K}$ эта реакция термодинамически возможна. В то же время, обратная реакция циклизации H-гексана с выделением водорода становится термодинамически закономерной только лишь начиная с температуры $1070^{\circ} \mathrm{K}$ (т. е. с $797^{\circ} \mathrm{C}$ ). Естественно, что такая температура в зоне нефтеобразования является невозможной.

Таким образом, с точки зрения термодинамики, в условиях температур поверхностной зоны земной коры невозможно ожидать процессов, приводящих к образованию циклических соединений из соединений с открытой цепью. И, наоборот, реакции дециклизации с образованием соединений с открытой цепью вполне закономерны.

Равным образом, частичное удаление водорода при помощи атмосферного (или в каком-либо другом виде) кислорода с целью получения олефинов, могущих далее циклизоваться, хотя и является термодинамически возможным благодаря высокой свободной энергии образования водяного пара, но в действительности вероятность такой реакции будет ничтожно малой. Известно, что продукты реакции дегидрирования - олефины гораздо более реакционноспособны по отношению к окислителям, чем исходные соединения, и будут окислены еще до циклизации.

Не трудно видеть, что правы те исследователи, которые видят путь метаморфизма нефтей от циклизованных, смолистых нефтей к нефтям метановым. Значит, неправы те исследователи, которые утверждают противоположную направленность изменения нефтей в природе.

Термодинамический подход позволяет дать строго научное объяснение фактам, связанным с особенностями состава нефтей. Было, например, неясно, почему не встречаются нефти, содержащие только лишь один тип углеводородов, например чисто ароматические нефти? Почему среди природных нефтей не встречаются нефти метаново-ароматического характера? Почему более древние, в геохимическом смысле, нефти всегда имеют более метанизированный характер? Были неясны и многие другие вопросы.

C точки зрения термодинамики нетрудно видеть, что ароматических нефтей в природе быть не может. Ароматические углеводороды обладают избытком свободной энергии по сравнению с другими классами органических соединений. Если бы даже нефтематеринское вещество дало исключительно ароматические углеводороды, то такая «нефть» была бы крайне недолговечной. Процессы диспропорционирования водорода, процессы дециклизации уже вскоре бы привели к образованию нафтеновых и, далее, метановых углеводородов - соединений менее энергонасыщенных. Равновесие установилось бы с образованием в этой системе всех трех классов углеводородов (в тех или иных соотношениях) и высокоуглеродистых циклизованных соединений со строением углеродного скелета типа графита. Неминуемо образовалось бы то или иное количество метана. Количественные соотношения между отдельными классами соединений в такой равновесной системе зависели бы от внешних условий температуры, давления, степени герметизации залежи и др. Задавшись 
определенными параметрами, в известных случаях можно даже рассчитать приблизительный состав равновесной смеси.

Строго говоря, в природных условиях при равновесии закономерна только система углеводородов из метана и его ближайших гомологов, вплоть до $\mathrm{C}_{6}$ (см. рис. 1). Ни чисто ароматических, ни чисто нафтеновых нефтей в природе быть не может.

Аналогичные рассуждения легко приводят к ответу и на второй вопрос. Система из метановых и ароматических углеводородов как естественноисторическое тело незакономерна. Нафтеновые углеводороды по запасам энергии занимают среднее положение между ароматическими и метановыми углеводородами. На какой бы стадии развития мы ни захватили систему, в начале состоящую лишь из ароматических и метановых углеводородов, в ней всегда будут содержаться нафтены.

Если учесть, что чисто метановый или чисто ароматический характер нефтематеринского вещества невозможен по геохимическим соображениям, а циклизация метановых углеводородов в нафтеновые исключается в условиях зоны нахождения нефти в земной коре (см. стр. 201), то станет очевидным, что исходное вещество, давшее то, что мы называем нефтью, носило именно полинафтеновый характер.

Мы видим, что в природе подавляющая масса нефтей (с учетом состава всех ее фракций). носит нафтеновый характер. Нафтеновым характером отличаются обычно нефти третичного возраста и значительная часть более древних нефтей. Такую особенность состава природных нефтей можно было предвидеть и легко объяснить. В самом деле, если нефтематеринское вещество имело циклизованный углеродный скелет, то дальнейшее развитие его могло пойти только лишь в единственном направлении - в направлении расходования соединений циклопарафинового характера с образованием, с одной стороны, высокоуглеродистых, высокоциклизованных соединений со скелетом графита и, с другой соединений метановых, с открытой цепью. Те и другие соединения на шкале свободных энергий лежат вблизи нулевых значений ее. Термодинамически неустойчивая система из соединений нафтенового строения медленно переходит в устойчивое состояние. Иногда этот процесс может ускоряться, иногда - замедляться. Однако в каждый данный момент в системе будут в наличии все три класса углеводородов и высокоуглеродистые вещества (асфальтово-смолистые вещества).

В силу местных особенностей легкоподвижные метановые углеводороды могут покинуть материнскую систему - рассеяться или дать начало образованию газового скопления, система может оставить на частицах породы асфальтово-смолистые вещества при своих передвижениях - во всех этих и других возможных случаях вторичные процессы будут накладывать свой отпечаток в каждый данный момент на состав нефти. Будут меняться порой весьма существенные детали, но общая направленность изменений нефти останется незыблемой. Чем глубже превращена нефть, тем больше в ней будет метановых углеводородов. Более древние нефти, при прочих равных условиях, в общем будут более метанизированы. Это и наблюдается в природе.

Термодинамический подход открывает пути к объяснению и других сторон состава нефти. Отсутствие в нефтях непредельных углеводородов, а также циклопарафинов с тремя и четырьмя атомами углерода в цикле становится понятным - эти соединения имеют относительно большой запас свободной энергии и имели достаточно времени, чтобы перейти в устойчивое состояние соединений с минимально-возможной свободной энергией. 
Известно, что в природных нефтях, среди производных бензола, а также циклопентана и циклогексана, более распространены полиметилпроизводные, чем соответствующие им по числу углеродных атомов алкилпроизводные. Рис. 1 убеждает нас в том, что первые из них имеют меньший запас свободной энергии и, следовательно, более устойчивы, чем вторые. Алкилпроизводные будут закономерно переходить в метилпроизводные (моно- и полипроизводные) с выделением избыточной энергии и попутным образованием метановых углеводородов.

Толуол, а также метил-циклометилены менее энергонасыщены и должны чаще встречаться в нефтях, чем голоядерные углеводороды - бензол, циклопентан и циклогексан. Так оно и естьвв природных нефтях.

Увеличение числа метильных групп в метилбензолах сопровождается снижением запаса свободной энергии вплоть до тетраметилбензола. Пента- и гексаметилбензолы уже более энергонасыщены. Поэтому можно довольно уверенно предположить, что в природных нефтях пента- и гексаметилбензолы не будут найдены, как они не найдены и до cero времени.

Алкилбензолы, начиная с бутилбензола, стоят на шкале свободных энергий выше бензола и всех других низкомолекулярных гомологов его. Этим и объясняется отсутствие в нефтях акилбензолов с цепью длинее пропила. Наоборот, в нефтях вполне закономерны многозамещен̈ные бензолы, вплоть до тетрапроизводных с короткими цепями.

В нефтях часто встречается цимол (пара-метил-изопропилбензол), в то время как изомерный ему бутилбензол не найден. Разгадка этого явления проста. Бутилбензол имеет свободную энергию в 31000 кал/моль, а цимол - 28600 кал/моль. Естественно ожидать внутримолекулярной перегруппировки возникшего на каком-то этапе бутилбензола в цимол. Этот простой акт освободит 2400 кал/моль энергии. С другой стороны, при образовании соединения общей формулы $\mathrm{C}_{10} \mathrm{H}_{14}$ будет исключительно образовываться цимол, а не бутилбензол, так как образование первого потребует меньшего количества энергии. Поэтому в нефтях и не найден бутилбензол, а место его занимает менее энергонасыщенный цимол.

Для нафтеновых углеводородов также можно предсказать некоторые закономерности и объяснить наблюдавшиеся явления.

Нафтены циклопентанового и циклогексанового рядов близко стоят друг к другу по величине свободной энергии. Следовательно, в общем случае с равным основанием можно предвидеть наличие в нефтях представителей обоих рядов. Так оно и есть на самом деле.

Работами ГрозНИИ $\left({ }^{8}\right)$ было показано, что в типично нафтеновых нефтях преобладают гомологи циклогексана, в то время как в метановонафтеновых нефтях больше гомологов циклопентана. Иными словами, нефти более превращенные (метанизированные) содержат больше циклопентанов, чем нефти менее превращенные (менее метанизированные).

В последних преобладают производные циклогексана. Одним из нас это объяснялось двояко: или 1) как следствие большей устойчивости циклопентанового ядра в процессах превращения нефтей, или 2) как результат относительного повышения содержания циклопентановых гомоголов за счет дополнительного появления их в позднейших процессах выделения моноциклических систем из более сложных молекул.

Представляется возможным и третье объяснение. Можно предполагать, что обогащение метанизированных нефтей циклопентанами имеет в своей основе энергетические причины. Нетрудно видеть, что алкилциклогексаны на шкале свободной энергии лежат между нормальными парафинами (метановыми углеводородами) и алкилциклопентанами.

Повидимому, первичными в нефтях являются производные цикло- 
гексана. В-этом случае процессы метанизации нефти, связанные с раскрытием гексаметиленовых циклов, приведут к выделению свободной энергии. Әта избыточная энергия может частично (а в известных случаях - главным образом) остаться внутри системы и приведет к перегруппировке гексаметиленов в пентаметилены с поглощением энергии. Произойдет внутрисистемное перераспределение энергии с образованием из исходных молекул соединений с большим и меньшим запасом энергии. Примеры таких процессов диспропорционирования массы известны (например, перераспределение водорода), а значит с этими процессами связано и перераспределение энергии. Таким образом, процесс метанизации нефти, как правило, должен сопровождаться увеличением (абсолютным и относительным) содержания в нефти циклопентанов.

Поступила в редакцию 14 XII 1953

\section{ЛИТЕРАТУРА}

1. А. Ф. Добрян ски й, Геохимия нефти, Гостоптехиздат, М.-Л., 1948.

2. И. Гу у ен, Методы органической химии, т. II, вып. 1, Госхимиздат, М.-Л., 194I.

3. В. В. Корбов, А. В. Фрост, Свободные энергии органических соединений, ВХО им. Менделеева, М., 1949.

4. П. Н. Л а з а р е в, Современные проблемы биофизики, Изд. АН СССР, М.-Л., 1945.

5. С. Н. Обрядчиков, Температурные условия образования нефти в природе, «Нефтяное хозяйство», № $3-4,1946$.

6. Г. Паркс, Г. Хаффман, Свободные энергии органических соединений, ОНТИ, 1936.

7. Сборник «Физико-химические свойства индивидуальных углеводородов», вып. I-III, Госхимиздат, М.-Л., 1945, 1947, 1951.

8. Сборник «Химический состав нефтей», ГрозНИИ, 1935.

9. А. В. Ф рост, Содержание в нефтях гексанафтенов как мера температуры образования нефти, «Нефтяное хозяйство», № $3-4,1946$. 